Editor's Note: These short reviews of a recent paper in the Journal, written exclusively by graduate students or postdoctoral fellows, are intended to mimic the journal clubs that exist in your own departments or institutions. For more information on the format and purpose of the Journal Club, please see http://www.jneurosci.org/misc/ifa_features.shtml.

\title{
p38 Mitogen-Activated Protein Kinase: A Novel Modulator of Hyperpolarization-Activated Cyclic Nucleotide-Gated Channels and Neuronal Excitability
}

\author{
Patricia Wynne \\ Graduate Program in Neurobiology, Brudnick Neuropsychiatric Research Institute, University of Massachusetts Medical School, Worcester, Massachusetts \\ 01605 \\ Review of Poolos et al. (http://www.jneurosci.org/cgi/content/full/26/30/7995)
}

Hyperpolarization-activated cyclic nucleotide-gated $(\mathrm{HCN})$ channels are permeable to $\mathrm{Na}^{+} / \mathrm{K}^{+}$and underlie the inwardly rectifying current termed $I_{\mathrm{h}}, I(\mathrm{f})$, or $I_{\mathrm{q}}$ (Santoro and Tibbs, 1999). Regulated by voltage and the binding of ligands, there are four $\mathrm{HCN}$ isoforms that vary in their activation kinetics. These currents contribute to the control of excitability, plasticity, and rhythmicity in cardiac cells and neurons throughout the CNS. In hippocampal pyramidal neurons, cAMPinsensitive $I_{\mathrm{h}}$ currents affect input resistance (IR) and temporal summation (TS) of EPSPs, thereby influencing dendritic synaptic integration. The kinetics and distribution of $I_{\mathrm{h}}$ are the principal factors influencing temporal summation and subsequent synchronization of CA1 hippocampal neurons (Magee, 1999). Recent studies have implicated these channels in learning and memory (Nolan et al., 2003) and the pathophysiology of diseases involving neuronal excitability such as epilepsy (Ludwig et al., 2003). Based on data from excised patches of exogenously expressed $\mathrm{HCN} 1$ or HCN2 channels, which display a hyperpolarized shift in voltage-dependent

\footnotetext{
Received Sept. 5, 2006; revised Sept. 20, 2006; accepted Sept. 22, 2006 Correspondence should be addressed to Patricia Wynne, Graduate Program in Neurobiology, Brudnick Neuropsychiatric Research Institute, University of Massachusetts Medical School, 303 Belmont Street, Worcester, MA 01604. E-mail: patricia.wynne@umassmed.edu.

DOI:10.1523/JNEUROSCI.3852-06.2006

Copyright $\odot 2006$ Society for Neuroscience $\quad$ 0270-6474/06/2611253-02\$15.00/0
}

activation independent of cAMP activity, Poolos et al. (2006) hypothesized that alternative proteins associated with the membrane patch contribute to the regulation of $I_{\mathrm{h}}$ activity. To determine modulators of $\mathrm{HCN}$ activity, in their recent paper in The Journal of Neuroscience, Poolos et al. (2006) identify p38 mitogen-activated protein kinase (MAPK) through computational analysis and examined its effects on $I_{\mathrm{h}}$.

The authors initially screened and identified 12 potential kinase modulators of HCN1 and HCN2 using the Scansite software tool [Poolos et al. (2006), their Table 1 (http://www.jneurosci.org/cgi/ content/full/26/30/7995/T1)]. Based on the highest level of stringency and likelihood of interaction with HCN1 and $\mathrm{HCN} 2$, the authors chose to examine the modulatory effect of p38 MAPK. Using adult rat hippocampal slices, the authors examined $I_{\mathrm{h}}$ in CA1 pyramidal dendrites and pyramidal-like principal (PLP) neurons. Although biocytin fills of these neurons showed a similar apical dendritic morphology [Poolos et al. (2006), their Fig. 1 A, B (http://www.jneurosci.org/cgi/ content/full/26/30/7995/F1)], these two cell types had opposite somatodendritic $I_{\mathrm{h}}$ distributions. CA1 neurons had a high dendritic and low somatic $I_{\mathrm{h}}$ density, whereas PLP neurons had a high somatic $I_{\mathrm{h}}$ density, allowing the authors to examine $I_{\mathrm{h}}$ in somatic recordings. In both cell types, macroscopic $I_{\mathrm{h}}$ currents were re- corded in cell-attached patch-clamp mode at various hyperpolarizing potentials, and the activation kinetics were fitted with a double exponential. The biophysical properties of $I_{\mathrm{h}}$ currents were similar in maximal density, voltagedependent activation [Poolos et al. (2006), their Fig. 1C (http://www.jneurosci.org/cgi/ content/full/26/30/7995/F1)] and activation kinetics [Poolos et al. (2006), their Fig. $1 D$ (http://www.jneurosci.org/cgi/content/ full/26/30/7995/F1)]. The fast kinetics of these channels suggest that CA1 dendritic and PLP somatic $I_{\mathrm{h}}$ currents are attributable to the HCN1 subtype. Also consistent with the HCN1 phenotype, $I_{\mathrm{h}}$ activation in CA1 dendrites was unaltered after application of a cAMP analog [Poolos et al. (2006), their Fig. $2 E$ (http://www.jneurosci.org/cgi/ content/full/26/30/7995/F2)].

To test whether modulation of $\mathrm{p} 38$ MAPK affected $I_{\mathrm{h}}$, the authors inhibited p38 MAPK with two specific cell-permeable inhibitors, 4-[5-(4-fluorophenyl)-2-(4[(S)-methylsulfinyl] phenyl)-3H-imidazol4-yl]pyridine (SB203580) and SB202190 [4-(4-fluorophenyl)-2-(4-hydroxyphenyl)-5-(4-pyridyl) $1 H$-imidazole]. In both cell types, MAPK inhibition resulted in a leftward shift in voltage-dependent activation, indicating that more hyperpolarized potentials elicited $I_{\mathrm{h}}$ current $\left(V_{1 / 2}\right.$ decreased $\sim 25 \mathrm{mV}$ ) [Poolos et al. (2006), their Fig. 2A,B (http://www.jneurosci. org/cgi/content/full/26/30/7995/F2)]. 
Pharmacological inhibition of two MAPK family members, ERK 1/2 (extracellular signal-regulated kinase $1 / 2$ ) and c-Jun $\mathrm{N}$ terminal protein kinase (JNK), or an inactive MAPK inhibitor analog did not affect $I_{\mathrm{h}}$ activation [Poolos et al. (2006), their Fig. 2C,D (http://www.jneurosci.org/cgi/ content/full/26/30/7995/F2)]. Anisomycin, an MAPK and JNK activator, resulted in a depolarizing shift in $I_{\mathrm{h}}$ activation of $\sim 11$ $\mathrm{mV}$ in PLP neurons [Poolos et al. (2006), their Fig. 2 F (http://www.jneurosci.org/ cgi/content/full/26/30/7995/F2)]. The authors argue that, because JNK inhibition did not modulate $I_{\mathrm{h}}$ activation, anisomycin must act to upregulate $I_{\mathrm{h}}$ via activation of p38 MAPK. These experiments show that resting levels of activated MAPK dynamically modulate $I_{\mathrm{h}}$ activation. It would be interesting to see whether the effects of the antiepileptic drug lamotrigine, which the authors mention shifts $I_{\mathrm{h}}$ activation in a depolarized direction, can be abolished by coapplication with SB203580.

Next, the authors assessed whether IR and TS would be altered by modulating p38 MAPK levels. The MAPK inhibitor SB203580 caused $\sim 72$ and $\sim 85 \%$ increase in IR in CA1 dendrites and PLP neurons, consistent with a decrease in active $I_{\mathrm{h}}$ [Poolos et al. (2006), their Fig. 4 (http://www.jneurosci.org/cgi/content/ full/26/30/7995/F4)]. Also consistent with a decrease in $I_{\mathrm{h}}$, SB203580 caused $\sim 16$ and $\sim 25 \%$ increase in the TS of a series of EPSPs [Poolos et al. (2006), their Fig. 5 (http://www.jneurosci.org/cgi/content/full/ 26/30/7995/F5)]. To determine whether the changes in IR and TS were specific to $I_{\mathrm{h}}$, the authors blocked $I_{\mathrm{h}}$ in PLP neurons with $N$-ethyl-1,2-dimethyl-6-methylimino- $N$ phenyl-pyrimidin-4-amine hydrochloride (ZD7288) which caused an increase of

A



Figure 1. Overview of $38 \mathrm{MAPK}$ regulation of $\mathrm{h}_{\mathrm{h}}$ activation at a membrane potential $\left(V_{\mathrm{h}}\right)$ of $-80 \mathrm{mV}$ in hippocampal neurons. $\boldsymbol{A}$, The majority of HCN channels remain in the closed state when p38 MAPK is pharmacologically inhibited by SB203580. $\boldsymbol{B}$, In contrast, at the same membrane potential, HCN channels open when p38 MAPK is activated by anisomycin.

$162 \%$ in IR and $41 \%$ in TS. Coapplication of SB203580 and ZD7288 caused no significant change in IR or TS, indicating that effects of MAPK inhibition on IR/TS were dependent on intact $I_{\mathrm{h}}$. Conversely, to determine the effects of MAPK activation on IR and TS, PLP neurons were intracellularly perfused with activated $\mathrm{p} 38 \alpha$ MAPK. Consistent with an upregulation of $I_{\mathrm{h}}$, a decrease in IR and TS was observed [Poolos et al. (2006), their Fig. 6 (http:// www.jneurosci.org/cgi/content/full/26/ 30/7995/F6)], further confirming the role of p38 MAPK in modulation of voltagedependent activation of $I_{\mathrm{h}}$ in pyramidal neurons.

Poolos et al. (2006) provide the first evidence that p38 MAPK robustly regulates $I_{\mathrm{h}}$ activity, shifting the number of channels active at the resting membrane potential and thus profoundly affecting hippocampal neuronal excitability (illustrated in Fig. 1). Although it is unknown whether p38 MAPK directly phosphorylates HCN channels, Poolos et al. (2006) pave the way for such studies. Furthermore, these results identify p38 MAPK as a potential therapeutic target for diseases such as epilepsy and cardiac arrhythmia in which HCN channels have been implicated.

\section{References}

Ludwig A, Budde T, Stieber J, Moosmang S, Wahl C, Holthoff K, Langebartels A, Wotjak C, Munsch T, Zong X, Feil R, Lancel M, Chien K, Konnerth A, Pape H, Biel M, Mofmann F (2003) Absence epilepsy and sinus dysrhythmia in mice lacking the pacemaker channel HCN2. EMBO J 22:216-224.

Magee J (1999) Dendritic $I_{\mathrm{h}}$ normalizes temporal summation in hippocampal CA1 neurons. Nat Neurosci 2:508-514.

Nolan M, Malleret G, Lee K, Gibbs E, Dudman J, Santoro B, Yin D, Thompson R, Siegelbaum S, Kandel E, Morozov A (2003) The hyperolarization-activated $\mathrm{HCN} 1$ channels is important for motor learning and neuronal integration by cerebellar Purkinje cells. Cell 26:551-564.

Poolos NP, Bullis JB, Roth MK (2006) Modulation of h-channels in hippocampal pyramidal neurons by $\mathrm{p} 38$ mitogen-activated protein kinase. J Neurosci 26:7995-8003.

Santoro B, Tibbs G (1999) The HCN gene family: molecular basis of the hyperpolarizationactivated pacemaker channels. Ann NY Acad Sci 30:741-764. 